\title{
A REFORMA POLÍTICA E O VOTO DISTRITAL
}

\author{
Lucas Ferreira Furlan \\ Universidade do Oeste Paulista - UNOESTE. Curso de Direito, Presidente Prudente - SP. E-mail: \\ lucasfurlan94@hotmail.com
}

\section{RESUMO}

No presente artigo trataremos do tema da reforma política no Brasil sobre tudo na possibilidade da implantação do sistema de voto distrital para as eleições legislativas, falaremos sobre o sistema proporcional que é atualmente adotado, destacando como ele funciona e apontando a nosso ver seus pontos falhos, como o fato de deputados com pequenas votações conseguirem se eleger pelo uso dos votos da legenda partidária, logos depois analisaremos a fundo o sistema distrital, destacando seus pontos positivos e também suas falhas é problemas que o Brasil pode enfrentar tendo uma vez implantado o respectivo sistema eleitoral, como, v. g. o número excessivo de partidos políticos. Encerramos com os outros temas em que nossa opinião devem ser debatidos durante o processo de reforma política e nossas conclusões sobre a implantação do voto distrital. Palavras- chave: Voto, Parlamento, Eleições, Sistema e Distritos.

\section{POLICY REFORM AND THE DISTRICT VOTE}

\begin{abstract}
In this article we tackle the issue of political reform in Brazil on everything in the possibility of implementing a district voting system for parliamentary elections, will talk about the proportional system that is currently adopted, highlighting how it works and pointing in our view their weak points, as the fact that MPs with small voting manage to elect the use of the votes of party label, logos then analyze in depth the district system, highlighting its strengths and its flaws are also problems that Brazil may face having once deployed its system election, for example the excessive number of political parties. We close with the other topics in our opinion should be discussed during the process of political reform and our conclusions about the implementation of the district vote.

Keywords: Voting, Parliament, Elections System and Districts.
\end{abstract}




\section{INTRODUÇÃO}

Desde a redemocratização o Brasil nunca esteve tão perto de realizar a tão esperada reforma política como está hoje, motivados ou até mesmo pressionados pelos protestos que varrerão o país em junho do ano passado, pela pressão da mídia e pelo aumento da preção popular, os parlamentares tem se empenhado em fazer andar o projeto no Congresso Nacional e este tem se tornado uma das principais bandeiras das campanhas dos parlamentares e até das presidenciais dentre as modificações que podem ser adotadas como o fim da reeleição para cargos do executivo, termino da suplência de senadores e até das coligações partidárias a que para nos mais parece importante e significativa é a adoção do voto distrital para os cargos do legislativo.

Neste artigo teremos o objetivo de discorrer sobre as falhas do sistema proporcional que é atualmente adotado e também sobre as vantagens e desvantagens da adoção do Sistema Distrital no Brasil.

\section{METODOLOGIA}

\section{O Sistema Atual}

O Sistema Proporcional que é atualmente utilizado no Brasil para as eleições parlamentares é originário da Bélgica, tendo sido criado entre o fim do século XIX e início do século XX, com o intuito de aumentar a representatividade das minorias, sendo este sistema adotado por um grande número de países principalmente após a Primeira Guerra Mundial, pelo sistema proporcional é estabelecido uma ponderação entre o numero de votos válidos o número de cadeiras disponíveis no parlamento e o numero de votos que o partido ou coligação obteve.

Funciona da seguinte forma o numero de votos válidos destinados ao legislativo é dividido pelo numero cadeiras disponíveis no parlamento, alcançado-se assim o coeficiente eleitoral. Após isto é preciso se alcançar o coeficiente partidário que é o resultado da divisão do numero de votos conferidos ao partido ou coligação pelo coeficiente eleitoral o resultado deste calculo desprezando a sobra será equivalente ao numero de cadeiras alcançadas pela legenda. Assumindo-as os candidatos que dentro da legenda obtiveram o maior numero de votos

A grande crítica a este sistema está no fato deque muitas vezes dentro das coligações ou partidos alguns candidatos obtém votações recordes e com isso acabam elegendo colegas que obtiveram votações pouco expressivas em detrimento de candidatos de outras legendas que obtiveram votações melhores.

O caso de maior destaque no Brasil ocorreu nas eleições de 2002 quando o candidato do partido nanico PRONA Dr. Eneas alcançou a votação recorde com mais de 1,55 milhão de votos e 
com isso conseguiu eleger consigo outros cinco candidatos de seu partido, sendo que deste quatro não chegaram perto de obter 1 mil votos.

Isso gera uma verdadeira crise de representação no pais, para se ter uma idéia nas eleições de 2010 apenas 35 dos 513 deputados foram eleitos com votos próprios, ou seja, algo entorno de míseros 7\% das cadeiras da Câmara dos Deputados são ocupadas por parlamentares que de fato conseguiram angariar votos para lá estar.

Números como estes fazem com que a adoção do voto distrital em uma eventual reforma política se torne o centro dos debates; no próximo tópico falaremos sobre o como funciona o sistema e suas vantagens e desvantagens.

\section{O Sistema Distrital}

Por este sistema o colégio eleitoral é dividido em tantas quanto forem as cadeiras em disputa no parlamento e cada partido político pode lançar um candidato em cada distrito sendo a eleição feita pelo sistema majoritário, ou seja, vence quem obtiver o maior número de votos.

O sistema distrital foi implantado de varias formas pelo mundo, na tentativa de corrigir alguns erros encontrados, as maiores criticas ao sistema são as de que as minorias sentem dificuldade em eleger candidatos neste sistema e que muitas vezes o como existe um grande numero de candidatos por distrito o que é de fato eleito possui uma votação muito inferior a maioria de eleitores da localidade.

Para tentar sanar esses problemas alguns países implantaram o chamado sistema distrital misto onde parte das cadeiras é preenchida pela eleição majoritária no distrito e a outra parte pela eleição proporcional que pode ser feita somente no distrito ou em todo colégio eleitoral. No que diz respeito ao segundo problema foi implantado em diversos lugares o sistema de dois turnos, como já é feito no Brasil nas eleições dos cargos do executivo.

\section{RESULTADOS}

Mesmo com estas críticas ainda entendemos ser o sistema distrital o melhor caminho, já que este amplia a participação popular no governo e aproxima o representado do representante, visto que a base eleitoral de cada candidato será bem menor este não poderá dela se afastar e os cidadãos terão mais facilidade e sobre tudo poder de cobrança sobre seus parlamentares.

Quanto os problemas apontados acima entendemos serem estes de fácil solução o da representatividade das minorias será solucionado com o tempo como cada partido poderá lançar um candidato por distrito, não demorará muito tempo para estes grupos conseguirem estabelecer 
suas bases em diversos locais do colégio eleitoral. Quanto ao problema da votação pequena obtida por quem é eleito, este pode ser solucionado com a implantação se um segundo turno dentro do distrito em que o mais votado não conseguir obter mais da metade dos votos validos, como alias já é feito para presidente, governador e nos municípios que possuem mais de duzentos mil eleitores.

\section{DISCUSSÃO}

\section{O Numero Excessivo de Partidos Políticos}

Em nossa opinião o principal problema de implantação do sistema distrital no Brasil será excessivo numero de partidos políticos existentes no país, já que hoje existem 32 partidos e algo em torno de 10 em fase de criação, a maioria destes criados apenas para atender interesses o projetos pessoais de poder, sem ter nenhum compromisso ideológico com as suas supostas bandeiras.

Usando estes números vejamos um exemplo, o estado de Sergipe é o menor do Brasil em dimensões geográficas, e tem direito a oito cadeiras na Câmara dos Deputados, ou seja, uma vez implantado o sistema distrital o estado seria dividido em oito distritos eleitorais, imaginando que cada partido lance um candidato por distrito o que provavelmente deve acontecer teremos somente no estado de Sergipe duzentos e cinqüenta e seis candidatos a deputado federal. Se fizermos a mesma conta em São Paulo maior colégio eleitoral do país com direito a setenta cadeiras na Câmara dos Deputados chegaremos a numero absurdo de dois mil duzentos e quarenta candidatos a deputado federal, somente no estado.

Como a Câmara dos Deputados possui hoje 513 cadeiras se cada um dos 32 partidos lançassem um deputado por distrito em todos os distritos do país chegaríamos a um total de dezesseis mil quatrocentos e dezesseis candidatos a deputado disputando uma cadeira na Câmara Federal.

Em nosso entender mesmo com a implantação de um segundo turno não seria suficiente para sanar o problema da representatividade já que devido ao expressivo numero de candidatos o numero de votos seria extremamente dissolvido no primeiro turno, de forma que seria totalmente questionável a representatividade presente naqueles que fossem disputar o segundo escrutínio.

O pluripartidarismo é uma importante garantia assegurada pela nossa Constituição, mas já estamos chegando á um ponto ridículo com um número extremamente excessivo de partidos, que na imensa maioria dos casos são criados somente para atender interesses momentâneos de políticos poderosos, ou para depois serem usados como moeda de troca para a obtenção de 
cargos e apoios políticos em eleições. O interessante é que mesmo com este numero de partidos a grande maioria da população não se sente representada no Congresso Nacional, um claro sinal de que a reforma política precisa ser feita e rápido.

\section{Gerrymandering}

Um grande problema que existe em alguns países que adotam o sistema distrital é a prática do gerrymandering, que nada mais consiste na divisão do colégio eleitoral em distritos que venham a favorecer este ou aquele partido, ou seja, uma área que tende a votar no partido " $\mathrm{A}$ " é dividida em vários distritos e outra que tende a votar no partido " $\mathrm{B}$ " é fatiada e suas partes incorporadas a outros distritos que tem uma tendência maior a votar no partido adversário, dessa forma mesmo que o partido "B" consiga maioria de votos na contagem geral do colégio eleitoral não conseguira maioria no parlamento porque perderá nos distritos.

Essa prática foi usada recentemente na Venezuela, onde nas eleições de 2010 a oposição recebeu $52 \%$ dos votos validos, mas mesmo assim o partido governista obteve $60 \%$ das cadeiras do parlamento. A quem defenda que essa prática também foi usada no Brasil durante o regime militar, principalmente no caso da unificação do estado da Guanabara e do Rio de Janeiro, de modo a enfraquecer a votação do MDB então partido oposicionista ao regime.

O gerrymandering é dos principais problemas do sistema distrital, sempre destacado quando o assunto entre em discussão, mas pode ser contornado com a adoção do sistema distrital misto que reserva uma parte das cadeiras para serem disputadas pelo sistema proporcional ou com uma prévia regulamentação da delimitação dos distritos de acordo com a sua população.

\section{CONCLUSÃO}

Analisando a fundo a história percebemos que os países democráticos ao longo do tempo fizeram um grande esforço para adotar sistemas eleitorais que garantissem o maior respaldo popular possível a seus governos. Foi assim com a adoção inicialmente do sistema majoritário depois com a criação do proporcional e agora por fim com o distrital, sempre um vindo com a função de sanar os problemas dos outros.

Mas nem sempre isso foi possível já que os novos sistemas sempre acabam fazendo surgir novos problemas, ou seja, hoje já nos parece quase que impossível criar um sistema eleitoral perfeito e livre de falhas. Mas sim criarmos um com o menor número de falhas possíveis, um que alheias a nosso ver já foi criado o Distrital, destacamos aqui seus pontos positivos e também suas falhas. E com isso concluímos ser ele a solução para a eleição de parlamentares que não 
conseguem chegar a 100 votos como já acontecem e aqui destacamos, ou acabar com o número excessivo de partidos já que só os mais fortes e com respaldo popular conseguiriam sobreviver tendo que lançar candidatos em todos os distritos fazendo assim os chamados partidos de gaveta desaparecerem.

Temos ainda que lembrar que o presente artigo adotou somente a implantação o voto distrital, mas durante o processo de reforma política outros temas precisam ser colocados em debates como por exemplo, o fim da reeleição para cargos do executivo, o extinção do cargo de suplente de senador e até mesmo a criação de coligações partidárias.

Hoje infelizmente existe uma grande descrença popular com a política em nosso país, precisamos urgentemente fazer grandes reformas que tragam o povo para o centro do debate político, levar o embate de idéias para o mais perto possível das pessoas, e permitir que elas tenham meios acessíveis para cobrar os seus eleitos, isso é o que tem faltado em, é isso que em nossa opinião o voto distrital pode fazer.

\section{REFERÊNCIAS}

BRASIL. Constituição (1988). Constituição da República Federativa do Brasil. Brasília, DF: Senado, 1988.

CAPEZ, F. Sistemas Políticos. In: CAPEZ, F. Direito Constitucional Simplificado. São Paulo: Saraiva. 2013. P. $140-147$

DALLARI, D. A. Sistemas Eleitorais. In: DALLARI, D. A. Elementos da Teoria Geral do Estado. São Paulo: Saraiva. 2013. P. 190-197.

NOVELINO. M. Sistemas Eleitorais. In: NOVELINO. M. Manual de Direito Constitucional. Rio de Janeiro: Gen. Método. 2013. P. 679-691.

PINTO, C .C. Sistema Eleitoral Majoritário e Sistema Proporcional. In: PINTO, C .C. Curso de Teoria Geral do Estado. São Paulo: Atlas. 2013. P. 202-204. 